\title{
Peningkatan Kompetensi Guru Bimbingan dan Konseling dalam Parenting Education pada Tingkat Pendidikan Anak Usia Dini
}

\author{
Novi Andriati, Martin, Amelia Atika, Novi Wahyu Hidayati \\ Program Studi Bimbingan dan Konseling Fakultas Ilmu Pendidikan dan Pengetahuan Sosial \\ IKIP-PGRI Pontianak \\ Jalan Ampera No. 88 Pontianak \\ *E-mail: Novieandriaty@yahoo.co.id
}

DOI: https://doi.org/10.21107/pangabdhi.v6i2.7725

Naskah diterima 29 Juli 2020, Revisi 7 September 2020, Terbit 29 Oktober 2020

\begin{abstract}
Abstrak
Parenting education, merupakan pendidikan yang berkaitan dengan cara atau teknik pengasuhan atau mengasuh anak saat mereka tumbuh berkembang. Tujuan kegiatan ini ialah memberikan pelatihan dan pendampingan kepada orang tua dan guru dalam melaksanakan perawatan dan pengasuhan kepada anak di jenjang PAUD. Metode yang digunakan yaitu, 1) tahap perencanaan: wawancara dan observasi, 2) tahap kegiatan: ceramah, tanya jawab dan praktik, 3) tahap evaluasi: pendampingan intensif melalui grup whatsapp. Kegiatan ini diikuti oleh 3 guru dan 30 orang tua Kelompok Bermain Asy-Syifa Azzahra, yang beralamat di Jalan Yos Sudarso Pontianak Barat. Hasil kegiatan peserta 1) memahami parenting education 2) menyusun program bimbingan dan konseling dan parenting education.
\end{abstract}

Kata Kunci: bimbingan, konseling, parenting education, PAUD

\begin{abstract}
Parenting education, is an education related to the way or techniques of parenting or parenting as they grow. The purpose of this activity is to provide training and mentoring to the people and teachers in conducting care and parenting to the children at the PAUD level. The methods used are, 1) planning stages: Interviews and observations, 2) stage of activity: lectures, faqs and practices, 3) Evaluation phase: Intensive mentoring through the whatsApp group. This activity was attended by 3 teachers and 30 parents of the group playing Asy Syifa Azzahra, which is located on the street of Yos Sudarso West Pontianak. Results of participant 1 activities) understand parenting Education 2) to develop guidance and counseling programs and parenting education.
\end{abstract}

Keyword: guidance, counseling, parenting education, PAUD

\section{PENDAHULUAN}

Penyelenggaraan bimbingan dan konseling di PAUD berlandaskan pada undang-undang sistem pendidikan nasional nomor 20 tahun 2003 pasal 1 butir 1 yang berbunyi: "pendidikan adalah usaha sadar dan terencana untuk mewujudkan suasana belajar dan proses pembelajaran agar peserta didik secara aktif mengembangkan potensi dirinya untuk memiliki kekuata spiritual keagamaan, pengendalian diri, kepribadian, kecerdasan, akhlak mulia, serta keterampilan yang diperlukan dirinya, masyarakat, bangsa dan negara" merupakan salah satu bentuk pendidikan persekolahan yang menyediakan program dini bagi anak usia empat tahun sampai memasuki pendidikan dasar, usia enam tahun. Tujuan penyelenggaraan PAUD yaitu untuk membantu meletakan dasar kearah perkembangan sikap, kemampuan, keterampilan, dan daya cipta yang diperlukan oleh anak didik dalam menyesuaikan diri dengan lingkungannya dan untuk pertumbuhan serta perkembangan selanjutnya.

Kebutuhan akan layanan bimbingan di taman kanak-kanak muncul dari karakteristik dan masalah-masalah perkembangan yang terjadi pada masa kanak-kanak. Pada masa perkembangan anak taman kanak-kanak, masalah dapat menghambat pencapaian perkembangan masa berikutnya, dan juga mempengaruhi aspekaspek perkembangan lainnya terutama tentang memberi makan, memberi makan dan menggunakan metode permainan bagi (parenting). Ahmad (2015) menyatakan bahwa "Parenting adalah proses pembelajaran 
pengasuhan interaksi antara orang tua dan anak yang meliputi aktivitas memberi petunjuk, memberi makan, memberi pakaian, melindungi anak saat mereka tumbuh berkembang", di PAUD istilah parenting dikenal dengan parenting education, merupakan pendidikan yang berkaitang dengan cara atau teknik pengasuhan atau mengasuh anak saat mereka tumbuh berkembang, dalam parenting education ini memiliki tujuan meningkatkan pengetahuan dan ketrampilan orang tua dalam melaksanakan perawatan dan pengasuhan anak-anak mereka, serta meningkatkan kesadaran orang tua atau anggota keluarga lain sebagai pendidik yang pertama dan utama.

Orangtua dan sekolah harus memiliki keterkaitan yang kuat satu sama lain dalam pengasuhan anak. Hal ini sesuai dengan yang diungkapkan oleh Kadarharutami (2011) bahwa sekolah dan orangtua pada dasarnya memiliki keinginan yang sama dalam mendidik dan mengasuh anak usia dini, yaitu menyiapkan anak untuk dapat menghadapi kehidupan. Hanya saja, sekolah lebih khusus menyoroti kesiapan anak pelajaran di SD, begitu juga dengan orang tua hanya menyoroti anak menghadapi tantangan dalam kehidupannya secara keseluruhan. Adanya kesamaan tujuan ini seharusnya membuat kedua belah pihak dapat saling bahu membahu dalam pengembangan kemampuan anak usia dini.

Ade dan Dinno (2018) mengatakan bahwa pola asuh orang tua yang tepat dan sesuai bagi diri anak, akan mendukung perkembangan anak untuk mencapai sebuah prestasi. Dengan demikian anak dan orang tua dapat bekerja sama untuk membangun kesempatan saling membangun, sesuai dengan status dan perannya masing-masing. Choirun et.al (2018) mengatakan peningkatan kompetensi guru dalam pengajaran sangat penting, karena keberhasilan proses pembelajaran tergantung pada guru, dan diharapkan kedepan bunda-bunda PAUD dalam kegiatan pembelajaran selalu mengacu pada konsep pembelajaran anak usia dini yakni belajar sambil bermain serta harus sesuai dengan tahap pencapaian perkembangan anak usia dini.

\section{METODE}

Kegiatan pengabdian kepada masyarakat ini dilaksanakan pada tahun akademik 2019/2020 dengan sasarannya orang tua dan guru PAUD.Metode yang digunakan yaitu : (1) tahap perencanaan : wawancara dan observasi,; (2) tahap kegiatan: ceramah, tanya jawab dan praktik; (3) tahap evaluasi: pendampingan intensif melalui grup whatsapp. Kegiatan ini diikuti oleh 3 guru dan 30 orang tua kelompok bermain Asy-Syifa Azzahra, yang beralamat di jalan Yos Sudarso Pontianak Barat. Alat yang media yang digunakan dalam kegiatan ialah proyektor, laptop yang berisi materi dan poster berupa gambar tentang parenting. Sasaran kegiatan pekerjaan mitra tersaji pada Tabel 1 .

Tabel 1. Latar Belakang Pekerjaan Mitra

\begin{tabular}{|c|c|c|}
\hline No & Pekerjaan & Jumlah \\
\hline 1. & TNI/ POLISI & 2 \\
\hline 2. & Wiraswasta & 7 \\
\hline 3. & Guru & 8 \\
\hline 4. & Pegawai swasta & 9 \\
\hline 5. & ART & 7 \\
\hline
\end{tabular}

Tabel 2. Tahapan Pelaksanaan Kegiatan

\begin{tabular}{|c|c|c|}
\hline No & Tahap Kegiatan & Tugas \\
\hline 1 & Perencanaan & $\begin{array}{l}\text { Membentuk } \\
\text { kepanitiaan secara } \\
\text { terarah, panitia yang } \\
\text { sudah terbentuk segera } \\
\text { bekerja dengan } \\
\text { menyiapkan saran dan } \\
\text { prasarana yang } \\
\text { dibutuhkan dalam } \\
\text { pelaksanaan kegiatan } \\
\text { sesuai dengan jenis- } \\
\text { jenis parenting yang } \\
\text { akan dikembangkan } \\
\text { dari hasil identifikasi } \\
\text { kebutuhan. }\end{array}$ \\
\hline 2 & Kegiatan & $\begin{array}{l}\text { Keterlibatan semua } \\
\text { pihak dalam } \\
\text { pelaksanaan parenting } \\
\text { education. }\end{array}$ \\
\hline 3 & Evaluasi & $\begin{array}{l}\text { 1) Membuat skala } \\
\text { ketercapaian kegiatan, } \\
\text { 2) Membuat laporan } \\
\text { pertanggungjawaban } \\
\text { kegiatan. }\end{array}$ \\
\hline
\end{tabular}

\section{HASIL DAN PEMBAHASAN}

Kegiatan pengabdian kepada masyarakat merupakan salah satu kegiatan Tridharma Perguruan Tinggi, dimana kegiatan tersebut digunakan oleh civitas akademika IKIP PGRI Pontianak untuk menunjukkan peran aktifnya dalam pembangunan pada wilayah Kalimantan Barat khususnya Kota Pontianak. Kegiatan ini disinergikan oleh Lembaga Penelitian dan Pengabdian Kepada Masyarakat (LPPM) IKIP PGRI Pontianak Tahun Akademik 2019/2020. 
Tabel 3. Program Parenting Education PAUD

\begin{tabular}{|c|c|c|c|c|c|c|}
\hline No. & $\begin{array}{l}\text { Unsur } \\
\text { Kegiatan } \\
\text { Parenting }\end{array}$ & Nama Kegiatan & $\begin{array}{c}\text { Rencana } \\
\text { Kegiatan/Jenis } \\
\text { Layanan }\end{array}$ & Tujuan Program & Tema & Sasaran \\
\hline & $\begin{array}{l}\text { Kegiatan } \\
\text { Pertemuan } \\
\text { Orangtua }\end{array}$ & Kegiatan Curah Pendapat & Layanan konsultasi & $\begin{array}{c}\text { Agar orangtua } \\
\text { mendapat } \\
\text { pemahaman } \\
\text { tentang } \\
\text { pendidikan anak }\end{array}$ & Diriku & Orangtua anak \\
\hline & & Parenting Education & Seminar/workshop & $\begin{array}{l}\text { Agar orangtua } \\
\text { mendapat } \\
\text { pemahaman } \\
\text { tentang } \\
\text { pendidikan anak }\end{array}$ & Keluargaku & Orangtua anak \\
\hline \multirow[t]{2}{*}{2} & \multirow[t]{2}{*}{$\begin{array}{l}\text { Keterlibatan } \\
\text { Orangtua di } \\
\text { Kelas Anak }\end{array}$} & $\begin{array}{l}\text { Membantu pendidik dalam } \\
\text { proses pembelajaran } \\
\text { dikelas }\end{array}$ & $\begin{array}{c}\text { Layanan informasi } \\
\text { tentang pendidikan } \\
\text { anak }\end{array}$ & $\begin{array}{c}\text { Agar orangtua } \\
\text { mendapat } \\
\text { pemahaman } \\
\text { tentang } \\
\text { pendidikan anak. }\end{array}$ & $\begin{array}{l}\text { Lingkungan } \\
\text { Kelas }\end{array}$ & $\begin{array}{l}\text { Orangtua dan } \\
\text { anak }\end{array}$ \\
\hline & & Parenting Class & Layanan informasi & $\begin{array}{c}\text { Agar orangtua } \\
\text { mendapat } \\
\text { pemahaman } \\
\text { tentang } \\
\text { pendidikan anak }\end{array}$ & Keluargaku & Orangtua \\
\hline \multirow[t]{4}{*}{3} & \multirow[t]{4}{*}{$\begin{array}{c}\text { Keterlibatan } \\
\text { Orangtua } \\
\text { dalam Acara } \\
\text { Bersama }\end{array}$} & $\begin{array}{l}\text { Kegiatan perayaan hari } \\
\text { besar }\end{array}$ & Layanan informasi & $\begin{array}{c}\text { Untuk } \\
\text { menumbuhkan } \\
\text { rasa nasionalisme } \\
\text { pada anak dan } \\
\text { orangtua }\end{array}$ & Negaraku & Orangtua anak \\
\hline & & $\begin{array}{l}\text { Kegiatan kunjungan } \\
\text { edukasi }\end{array}$ & Tour Education & $\begin{array}{c}\text { Pengenalan } \\
\text { tentang alam dan } \\
\text { sekitarnya }\end{array}$ & $\begin{array}{l}\text { Binatang dan } \\
\text { Tanaman }\end{array}$ & Orangtua anak \\
\hline & & Demo Masak / Cooking & $\begin{array}{l}\text { Layanan informasi } \\
\text { untuk } \\
\text { memperkenalkan } \\
\text { anak tentang } \\
\text { makanan }\end{array}$ & $\begin{array}{c}\text { Tercipta suasana } \\
\text { keakraban antara } \\
\text { orangtua, guru } \\
\text { dan anak agar } \\
\text { kreatifitas anak } \\
\text { optimal. }\end{array}$ & Keluargaku & $\begin{array}{l}\text { Anak dan } \\
\text { Orangtua }\end{array}$ \\
\hline & & Kegiatan outbond & Layanan orientasi & $\begin{array}{c}\text { Agar terjalin } \\
\text { keakraban antara } \\
\text { orangtua, anak, } \\
\text { dan guru }\end{array}$ & Lingkungan & $\begin{array}{c}\text { Anak } \\
\text { danOrangtua }\end{array}$ \\
\hline 4 & $\begin{array}{c}\text { Hari } \\
\text { Konsultasi } \\
\text { Orangtua }\end{array}$ & $\begin{array}{c}\text { Konsultasi antara guru dan } \\
\text { orangtua }\end{array}$ & Layanan konsultasi & $\begin{array}{c}\text { Agar orangtua } \\
\text { mendapat } \\
\text { pemahaman } \\
\text { tentang } \\
\text { pendidikan anak. }\end{array}$ & Keluargaku & $\begin{array}{l}\text { Anak dan } \\
\text { Orangtua }\end{array}$ \\
\hline \multirow[t]{2}{*}{5} & \multirow[t]{2}{*}{$\begin{array}{l}\text { Kunjungan } \\
\text { Rumah }\end{array}$} & $\begin{array}{l}\text { Berbagi penglaman } \\
\text { peninggkatan gizi, } \\
\text { pemeliharaan kesehatan, } \\
\text { perawatan,pengasuhan, dan } \\
\text { pendidikan. }\end{array}$ & Home Visit & $\begin{array}{c}\text { Memberikan } \\
\text { informasi tentang } \\
\text { peningkatan gizi, } \\
\text { pemeliharaan } \\
\text { kesehatan, } \\
\text { perawatan, } \\
\text { pengasuhan, dan } \\
\text { pendidikan. }\end{array}$ & Keluargaku & Orangtua anak \\
\hline & & $\begin{array}{l}\text { Bermain bersama keluarga } \\
\text { (pendidikan orangtua) }\end{array}$ & $\begin{array}{c}\text { Layanan bimbingan } \\
\text { kelompok (topik } \\
\text { pendidikan orangtua) }\end{array}$ & $\begin{array}{c}\text { Menjalin rasa } \\
\text { kekeluargaan } \\
\text { antara orangtua, } \\
\text { anak, dan guru }\end{array}$ & $\begin{array}{c}\text { Keluargaku } \\
\text { (cara menjadi } \\
\text { orangtua yang } \\
\text { hebat) }\end{array}$ & Orangtua anak \\
\hline
\end{tabular}


Perencanaan dilakukan membentuk kepanitiaan secara terarah, panitia yang sudah terbentuk segera bekerja dengan menyiapkan saran dan prasarana yang dibutuhkan dalam pelaksanaan kegiatan sesuai dengan jenis-jenis parenting yang akan dikembangkan dari hasil identifikasi kebutuhan. Masing-masing seksi berfungsi sesuai dengan uraian tugas masingmasing (job description) yang sudah disusun. Tahapan persiapan dituangkan dalam prosedur kerja: (a) Panitia kegiatan menyiapkan format undangan rapat persiapan; (b) Panitia kegiatan menentukan jenis kegiatan, waktu dan tempat kegiatan; (c) Panitia kegiatan mempersiapkan semua keperluan kegiatan; (d) Panitia kegiatan menentukan tugas masing-masing personil dalam kepanitiaan; (e) Panitia kegiatan melaksanakan kegiatan.

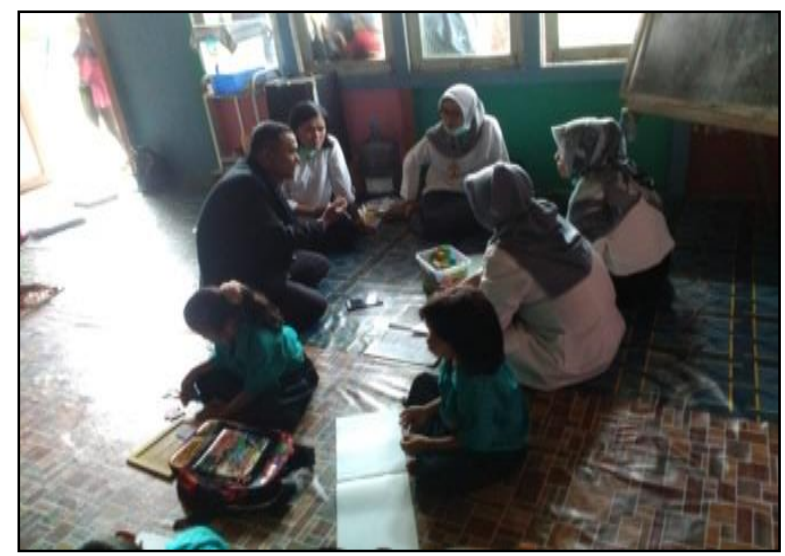

Gambar 1. Kegiatan Parenting Education

Partisipasi Mitra dalam Pelaksanaan, dalam pelaksanaan parenting education ini semua pihak harus terlibat, karena program ini dirancang untuk menguatkan pembentukan perkembangan anak (lingkungan rumah, lingkungan sekolah, lingkungan masyarakat/tempat tinggal anak). 1) Lingkungan rumah, adalah melibatkan seluruh anggota keluarga seperti ayah, ibu, kakek, nenek, paman, bibi, sopir, 2) Lingkungan sekolah, adalah melibatkan semua unsur dan sumber daya manusia di sekolah seperti kepala sekolah, guru, tenaga administrasi, tenaga kebersihan, dan semua yang ada dilingkungan sekolah, 3) Lingkungan masyarakat mencakup yang lebih luas, yaitu tempat tinggal anak tetangga, pembantu tetangga, sopir tetangga, teman sebaya, teman lebih tua, teman lebih muda, pedagang, dan komunitas masyarakat.

Setiap tahapan kegiatan dilakukan evaluasi dan monitoring yang bertujuan untuk menghindari penyimpangan dan kesalahan pelaksanaan kegiatan. Evaluasi dan monitoring dilakukan sejak persiapan sampai selesai kegiatan. Adapun langkah-langklah dalam evaluasi: 1) Membuat skala ketercapaian kegiatan, 2) Membuat laporan pertanggungjawaban kegiatan, 3) Pelaksana kegiatan membuat grup whatsapp untuk followup.

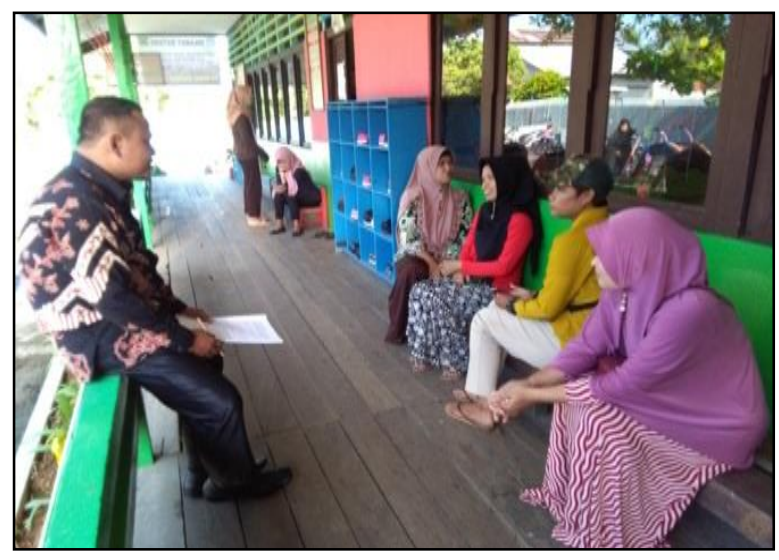

Gambar 2. Evaluasi Kegiatan

Konsep PAUD ialah terbentuk hasil interaksi individu dengan orang-orang lain yang berarti (significant others) dalam kehidupannya. Interaksi dengan orang-orang lain yang berarti inilah yang sebagian besar yang mempengaruhi perkembangan konsep diri, sehingga dapat terbentuk konsep diri yang cenderung positif dan negatif pada setiap individu. Sejalan dengan pendapat Ernawulan \& Mubiar (2008) menyatakan: "Perkembangan anak usia dini adalah anak yang memiliki ciri yang masih bersifat egosentris naif, relasi sosial yang primitif, kesatuan antara jasmani dan rohani yang hampir tidak terpisahkan, serta sikap hidup yang masih fisiognomis.

Perkembangan bersifat progresif, sistematis dan berkesinambungan. Adapun prinsip-prinsip adalah perkembangan berlangsung seumur hidup dan meliputi semua aspek perkembangan anak, setiap individu memiliki irama dan kualitas perkembangan yang berbeda, perkembangan yang relatif beraturan, mengikuti pola-pola tertentu, perkembangan berlangsung dari kemampuan yang bersifat umum menuju paada yang lebih khusus, mengikuti proses diferensiasi dan integrasi, secara normal perkembangan individu mengikuti seluruh fase sampai batasbatas tertentu, perkembangan sesuatu aspek dapat dipercepat atau diperlambat, perkembangan aspek-aspek tertentu berjalan sejajar atau berkorelasi dengan aspek lainnya, dan pada saat-saat tertentu dan dalam bidangbidang tertentu perkembangan pria berbeda dengan wanita. 


\section{KESIMPULAN}

Dari hasil kegiatan dapat disimpulkan termasuk dalam kategori baik dengan indikator: 1) $75 \%$ kelompok sasaran yaitu guru dan orang tua dapat berpartisipasi dalam kegiatan, 2) respon peserta peserta sangat antusia dalam mengikuti workshop dan pelatihan. Namun peserta masih perlu pendampingan dalam hal mengatur jadwal anak pada saat berada di rumah, dan keterlibatan orang tua dalam acara bersama.dikarenaka orang tua sibuk dengan pekerjaannya, sehingga sulit mengatur waktu bersama dengan anak dan membuat jadwal kegiatan sehari-hari. Hal ini sebagai bahan evaluasi terkait pemilihan keterkaitan pendukung kegiatan parenting education. Namun dengan melihat antusias peserta dalam mengikuti kegiatan ini, khususnya dalam kegiatan pelatihan tentang parenting perlu diadakan kegiatan serupa selanjutnya.

\section{DAFTAR PUSTAKA}

Ade, S \& Dinno, M. 2018. Program Parenting Dalam Meningkatkan Kualitas Pendidikan Keluarga (Program Pengabdian di Desa
Karangpakuan, Kecamatan Darmaraja, Kabupaten Sumedang). Jurnal Pengabdian Kepada Masyarakat (Abdimas) IKIP Siliwangi. Vol 1 (1). 22-30 pp.

Ahmad, S. 2015. Perkembangan Parenting Belajar Pada Anak Usia Dini. Jakarta: Kemendikbud.

Choirun, N., Vanda, R., \& Evi, D. 2018. Pengabdian Kepada Masyarakat Melalui Pendampingan Bagi Guru Pos PAUD. Jurnal Abadi. Vol 2 (2). 38-46 pp.

Kadarharutami. 2009. Konsep Dasar Pendidikan Anak Usia Dini. Jakarta: Indeks.

Sofyan. 2015. Konseling Keluarga. Bandung: Alfabeta.

Undang-Undang No 20 Pasal 1 Butir 1 Tentang Sistem Pendidikan Nasional. (2003). Jakarta: Kemendikbud. 